\title{
Bauhaus e o estilo moderno
}

\section{Bauhaus and the modern style}

Felipe Kaizer, Universidade Estadual do Rio de Janeiro, Brasil. fk@felipekaizer.com

\section{Resumo}

Neste artigo, investiga-se o uso ambíguo dos termos "estilo" e "arquitetura" em alguns escritos de Walter Gropius enquanto proponente, diretor e ex-diretor da escola alemã Bauhaus. Procurase revelar nos debates sobre o papel social da arte no século XIX as origens do sentido arquitetônico de estilo presente nesses escritos. Ademais, identifica-se a transformação desses conceitos na assimilação dos preceitos da Bauhaus e do Movimento Moderno nos Estados Unidos. Em suma, o apelo às noções de "estilo Bauhaus" e "estilo internacional" contrapõe-se substancialmente às proposições originais de Gropius. Sugere-se afinal uma retomada do estudo da reforma social da arte inglesa como etapa indispensável à compreensão do processo histórico que levou à criação da Bauhaus.

Palavras-chave: Design e Arquitetura, Movimento Moderno, História das Ideias

\begin{abstract}
In this article, we investigate the ambiguous employment of the terms "style" and "architecture" in some of the writings of Walter Gropius as a proponent, director and former director of the German school Bauhaus. In the debates about the social role of art in the $19^{\text {th }}$ century, we seek to reveal the origins of the architectural sense of style present in such writings. Besides, we identify the transformation of these concepts as the United States absorbs the precepts of the Bauhaus and the Modern Movement. In short, the appeal to the notions of "Bauhaus style" and "International Style" is substantially opposed to Gropius' original propositions. Finally, we suggest a return to the study of English social art reform as an indispensable step to understanding the historical process that led to the creation of the Bauhaus.
\end{abstract}

Keywords: Design and Architecture, Modern Movement, History of Ideas 
Walter Gropius combateu diversas vezes a tendência que a Bauhaus fosse reduzida a um estilo. Sobretudo a partir da segunda metade dos anos 1920, à medida que a experiência educacional em Weimar e Dessau se tornava mais conhecida internacionalmente, o "estilo Bauhaus" parecia a ele uma ameaça cada vez maior à compreensão das suas proposições. Em uma publicação de 1930, o ex-diretor da escola explicitou sua oposição:

$\mathrm{O}$ aspecto uniforme do trabalho [da Bauhaus] [...], apesar da diversidade de individualidades que trabalharam juntas, foi fruto de uma direção espiritual, desenvolvida conjuntamente [...], que finalmente teria superado o criar sob decreto de uma concepção estética-estilística no antigo sentido de "artesanal". Os livros da Bauhaus, a revista da Bauhaus e as palestras à noite na Bauhaus, já cultivadas em Weimar, mantiveram um complexo de questões afastado do assoreamento acadêmico e em vivaz movimento. Ao mesmo tempo, porém, a luta contra aplicações imitadoras e equivocadas teve de ser travada contra aqueles que queriam ver todos os edifícios e dispositivos dos tempos modernos que careciam de decoração afiliados a um "estilo Bauhaus", e ameaçavam achatar o sentido bem fundamentado do trabalho da Bauhaus. O objetivo da Bauhaus não é um "estilo", não é um sistema, dogma ou cânone, não é uma receita ou moda! (GROPIUS, 1930, p. 10-11) ${ }^{1}$

O estilo é tomado aqui em sua relação direta com o ensino acadêmico dos chamados estilos históricos. Por isso, Gropius proclama a Bauhaus "o primeiro instituto do mundo [...] a fixar sob à forma de escola essa postura antiacadêmica" (GROPIUS, 1930, p. 11). Logo, para ele, um estilo Bauhaus seria o equivalente a "um retrocesso à estagnação acadêmica" (GROPIUS, 1930, p. 11), isto é, àquela imitação nostálgica que considerava um sintoma da decadência da arte no seu tempo.

No entanto, a palavra estilo, ao menos até esse momento histórico, comportava mais de um sentido. De fato, observa-se um intercâmbio, para não dizer uma certa confusão, entre suas diferentes acepções, mesmo no discurso de Gropius. É, pois, preciso empreender um esforço de compreensão da determinação histórica dos sentidos da palavra para que se esclareça minimamente o sentido da oposição representada pela Bauhaus de Gropius.

Para efeito de contraste, basta tomar o memorando apresentado em 1910 ao industrial Emil Rathenau, no qual Gropius defende a constituição de uma empresa de casas pré-fabricadas industrialmente. No trecho publicado pela primeira vez por Hans Maria Wingler nos anos 1960, aparece uma determinada concepção de "estilo do tempo" (Zeitstil). Com essa expressão, Gropius refere-se a algo substancialmente diferente dos estilos históricos; ele tem em mente não uma forma específica copiável, mas um "princípio subjacente".

Uma convenção, no melhor sentido da palavra, não pode ser esperada por meio de uma ênfase na individualidade. Em vez disso, é resultado da conquista de uma integração que se desenvolve do ritmo da repetição e da uniformidade de formas comprovadas e recorrentes. Nossa era, após um triste interregno, está mais vez se aproximando de um estilo do seu tempo que honra a tradição, mas luta com o falso romantismo. (GROPIUS apud WINGLER, 1978, p. 20)

Esse estilo estaria ligado à certa ideia de regularidade e harmonia e condicionaria a criação de todos os objetos e construções. Não obstante, seria algo sensível à passagem do tempo, e que precisava ser buscado, criado e ensinado. Nem por isso o estilo do tempo seria buscado por

\footnotetext{
${ }^{1}$ Todas as traduções das citações em língua estrangeira são do autor deste artigo. As ênfases (em itálico) são as originais, exceto quando indicado "ênfase nossa".
} 
formas recorrentes específicas. Antes, permaneceria associado a uma ideia antiga de arquitetura, presente no discurso de Gropius ao longo do anos.

Essa ideia de estilo de caráter arquitetônico tinha sua origem mais imediata, como o próprio Gropius admitia, na Inglaterra do século anterior. Sua proposta de casas pré-fabricadas procurava levar adiante os experimentos de construção residencial em massa nos subúrbios ingleses. Ela tomava a uniformidade como princípio geral, mas mantinha a possibilidade de variações individuais. Esse foi o norte de projetos de Gropius anos depois, como a proposta de bairro exposta em 1923 na Exposição Internacional de Arquitetura em Weimar e as Casas dos Mestres da Bauhaus construídas em Dessau. Essencialmente, Gropius defendeu a tipificação não da forma final dos edifícios, mas do seu método de produção e montagem.

O que se investiga aqui, no entanto, é como o estilo moderno foi ora criticado como um signo de historicismo ou formalismo, ora defendido como um princípio fundamental à coerência entre o trabalho de vários artistas. Este artigo procura iluminar brevemente essa ambiguidade, tomando como material de investigação alguns escritos de Gropius e de outros autores dos séculos XIX e XX.

\section{O espírito arquitetônico}

A Bauhaus costuma ser rememorada por aquilo que legou, a saber, principalmente, um modelo educacional e uma ideia de linguagem visual. Mas seus objetivos eram mais amplos do que isso. Acima de tudo, ela visava produzir um "novo homem" para um "novo mundo" após a guerra, o que implicava uma educação voltada para o indivíduo e contraposta às academias de arte. E o visava através da união das artes, isto é, com o fim da separação entre as belas-artes e o artesanato. No entanto, há outro objetivo de importância ao menos equivalente: o desenho dos espaços e objetos que compunham a vida.

O conjunto articulado desses desígnios constituía aquilo que Walter Gropius nomeou de "arte arquitetônica moderna" (GROPIUS, 1955, p. 19). Para Gropius, sua expressão mais definitiva seria a própria arquitetura, ou o que ele originalmente chamou "construção" $(B a u)$. A rigor, a Bau seria um conceito mais amplo e abarcaria a arquitetura como disciplina, assim como a pintura, a escultura e os ofícios manuais (WINGLER, 1978, p. 26). De maneira análoga à palavra "estilo", a "arquitetura" possuía uma ambivalência: ora era uma arte do desenho comprometida com aspectos da vida prática (como definida pela tradição das artes e ofícios), ora era a epítome de uma arte geral da construção (Baukunst).

No manifesto de fundação da escola há uma imagem da construção que Gropius tinha em vista: a catedral, representada pela gravura de Lyonel Feininger. Ainda que sua referência fosse a Idade Média, tal catedral seria "a nova construção do futuro" (GROPIUS, 1919, p. 2). Para além desse paradoxo, ela simbolizava

[...] a reunião de toda criação artística em uma unidade, a reunificação de todas as disciplinas artísticas-produtivas - escultura, pintura, os ofícios artesanais e as artes manuais - em uma nova arte da construção [...]. O objetivo último, embora distante, da Bauhaus é a obra de arte una - a grande construção [...]. (GROPIUS, 1919, p. 3, ênfase nossa) 
A palavra utilizada por Gropius é Einheitskunstwerk. A tradução mais comum para o português é "obra de arte total" e faz referência à expressão de Richard Wagner, Gesamtkunstwerk (ARGAN, 2010, p. 440). No entanto, há uma diferença significativa. Wagner referia-se à reunião das artes no acontecimento singular da ópera - além da música e do teatro, a literatura, a pintura, a arquitetura etc. -, enquanto Gropius referia-se à integração das artes na manifestação unitária ou total da construção que embasa a vida cotidiana. Não há evidências de que Wagner pretendia fundar uma arte "todo-abrangente no seu escopo" e, portanto, coincidente com a própria "natureza humana" (GROPIUS, 1955, p. 20). Ao contrário, a ópera deveria continuar a ser um momento de exceção e redenção da vida burguesa.

A catedral gótica medieval foi, portanto, a primeira imagem da obra de arte una mencionada no manifesto. Ela foi apresentada em um contexto de crítica ao estado da arte contemporânea que teria se desviado do objetivo da "harmonia progressiva" de todos os elementos e partes da construção (GROPIUS, 1919, p. 3), com a separação entre arte e artesanato a partir do Renascimento italiano. Gropius propôs, assim, um retorno dos artistas às oficinas (em contraposição às academias e aos salões) e a um modelo prático e engajado de ensino. Nesse sentido, a imagem da catedral remete às Bauhütten, isto é, às comunidades medievais de artistas que juntos viviam e trabalhavam no canteiro de obras (WICK, 1989, p. 64). Nessa linha, em sua proposta de escola de 1916, Gropius expôs sua visão:

\begin{abstract}
Entre seus membros, uma parceria igualmente feliz poderá ressurgir como a praticada nas "cabanas" medievais, onde diversos artistas-artesãos - arquitetos, escultores e artesãos de todas as classes - se uniam em um espírito homogêneo e humildemente contribuíam com seu próprio trabalho às tarefas comuns diante deles. Isso era feito em respeito à unidade da ideia mútua que os inspirara e cujo sentido eles compreendiam. Com o renascimento de tais métodos de trabalho, já experimentados, a serem adotados de acordo com os meios do mundo contemporâneo, a imagem expressiva da nossa manifestação moderna da vida precisa ganhar uniformidade para que, mais uma vez, se funda em um "novo estilo" nos tempos vindouros. (GROPIUS apud WINGLER, 1978, p. 24)
\end{abstract}

As aspas denunciam um receio. Ainda assim, Gropius não encontrou outra expressão. Ademais, lê-se que esse retorno visava recuperar um modo pré-moderno de construir e trabalhar. Contudo, o objetivo fundamental era o de reencontrar uma união, uma unidade, uma uniformidade fundamental, sem a qual o trabalho dos artistas permaneceria desconexo e sem sentido. Isso explica que, para Gropius, "as 'artes' independentes [deveriam] ser libertas do seu isolamento e postas novamente em contato íntimo, sob o braço de uma grande arquitetura" (GROPIUS apud WINGLER, 1978, p. 26).

Logo, não obstante a menção no manifesto a "uma nova guilda de artesãos", em verdade, Gropius almejava certo "espírito arquitetônico" (GROPIUS, 1919, p. 2). O que essa expressão significava tornou-se evidente com a revisão da estrutura curricular da escola publicada em 1923, na qual Gropius pôs no seu centro o estudo da construção (Baulehre) (GROPIUS, 1923, p. 4). Até 1927, no entanto, o departamento de arquitetura propriamente dito continuou a ser apenas uma proposta. De toda forma, com essa formulação, Gropius não pretendia simplesmente "a melhoria das condições externas de vida", mas uma "mudança na postura interna do indivíduo em relação ao seu trabalho" (GROPIUS, 1923, p. 1). Tratava-se de incutir nos discípulos um espírito de outrora. Por detrás dessa proposição estava a crença de que "[o] sentimento do mundo de uma época cristaliza-se nitidamente nos seus edifícios" (GROPIUS, 
1923, p. 1). Isso não significava que o arquiteto fosse responsável sozinho pela forma unitária concreta do espírito do tempo, a despeito do que Gropius acreditava ou fazia pessoalmente, mas que "[a] arte de construir está ligada à possibilidade do trabalho conjunto de uma multiplicidade de criadores, pois suas obras [...] são de um tipo orquestrado e [...] um retrato do espírito da totalidade" (GROPIUS, 1923, p. 1). Afinal, a Bauhaus visava formar artistas que saberiam projetar "edifícios na sua totalidade - a construção básica, as expansões, a decoração e a mobília - de maneira uniforme a partir de um espírito de mesmo tipo" (GROPIUS, 1919, p. 3). Gropius baseava-se novamente na crença de que "[u]m espírito vivo de construção, enraizado na vida plena de um povo, abarca em seu domínio todas as áreas do desenho humano, todas as 'artes' e técnicas" (GROPIUS, 1923, p. 1).

\section{O revivalismo gótico}

Essa crença é anterior à Bauhaus. Segundo o cientista social Raymond Williams, a ideia de que as manifestações da arte, especialmente os edifícios públicos, sinalizam o estado moral e espiritual de uma nação pode ser remetida aos reformadores da cultura ingleses (WILLIAMS, 1960, p. 140). Entre eles, destaca-se Augustus Welby Northmore Pugin. Pugin propôs reavivar o estilo gótico como estilo nacional. Nos anos 1830, questões estéticas ainda estavam fortemente atadas a questões morais, religiosas e políticas. Pugin defendeu, naturalmente portanto, uma renovação do gosto público como uma renovação da substância ética do povo inglês. Depois dele, John Ruskin adicionou a essa formulação a ideia de que as condições sociais impostas pelo regime industrial de produção impossibilitariam em definitivo a produção artística. Em outras palavras, uma sociedade corrompida não seria capaz de produzir o Belo, o Bom e o Verdadeiro através dos seus artistas. Contudo, operou-se a partir daí uma inversão: aquilo que era visto como o signo de uma sociedade próspera passou a ser perseguido como um objetivo, como se o bom desenho dos edifícios e dos objetos que circundam a vida proporcionassem o bem viver.

Trata-se de uma inversão tipicamente moderna, pois baseada em uma mudança profunda do sentido da história. Em suma, os modernos viam não apenas os antigos, mas a si mesmos, com outros olhos, e, em sua suposta plena consciência da História, encontraram nos estilos históricos a integridade entre ética e estética que consideravam perdida na nova sociedade industrial. Resulta assim, no século XIX, uma sensibilidade baseada na rememoração do passado, mais exatamente, na sua revivescência: revival. A esse respeito, Pugin escreveu:

A história da arquitetura é a história do mundo: ao inspecionarmos os edifícios da antiguidade, suas nações, suas dinastias, suas religiões, tudo isso vem ao nosso encontro. As crenças e costumes de todos os povos estão encarnados nos edifícios que erigiram; era impossível para qualquer um deles ter construído consistentemente de outra maneira: cada um foi o inventor e o aperfeiçoador do seu estilo peculiar; cada estilo era a epítome da sua religião, dos seus costumes e do seu clima. (PUGIN, 1895, p. 4)

Emergiu daí o desejo de criar deliberadamente o estilo do próprio tempo. Isso explica que o impulso para o estilo moderno tenha nascido sob a marca do revivalismo. Pugin defendeu o gótico na Inglaterra como "a única expressão correta da fé, vontade e clima” do seu país (PUGIN, 1895, p. 4). Tal retorno, no entanto, teria de ser tanto no estilo quanto no espírito, pois a arquitetura do seu tempo estava "em um período de baixa" e assim permaneceria "a não ser 
que o mesmo sentimento que influenciou os antigos projetistas" pudesse ser restaurado (PUGIN, 1836, p. iii, ênfase nossa). Afinal, "é somente por meio de semelhante sentimento de glória que semelhantes resultados gloriosos podem ser obtidos" (PUGIN, 1836, p. iii).

Estabeleceu-se assim o social-reformismo inglês que serviu de base para a criação das primeiras schools of design em Londres e para o movimento Arts \& Crafts de William Morris. Sob os auspícios do Parlamento, já nos anos 1830, foram criadas as primeiras instituições dedicadas a educar o gosto do público e a formar os novos profissionais de projeto necessários à produção industrial de mercadorias rentáveis e adequadas à moral (ROMANS, 2005). Dando continuidade às propostas de Pugin, na segunda metade do século XIX, Morris defendeu uma prática artística integral e integrada com a vida, considerando o desaparecimento de uma tal prática desde o Renascimento.

$\mathrm{Na}$ sua fundação, a Bauhaus atacou o mesmo problema. Porém, à educação dos novos artistas, a escola acrescentou não apenas uma etapa preparatória (Vorlehre), mas também e sobretudo a consciência de um "novo espírito de construção". Aqui Gropius ecoou o argumento de Pugin: "Como a construção é um trabalho coletivo, seu bom desenvolvimento depende não do indivíduo, mas do interesse do todo. A construção pura livre de propósito ${ }^{2}$ é resultado apenas da vontade de um povo inteiro" (GROPIUS, 1923, p. 9)

Isso explica o uso do termo "arquitetura" tanto em Pugin quanto em Gropius. Ambos faziam referência a uma concepção antiga da disciplina, cuja etimologia revela um caráter abrangente. Em grego, arkhé designa princípio ou aquilo que vem primeiro e tem primazia sobre o restante, e téktōn o carpinteiro, aquele cuja prática consiste em criar, gerar ou produzir (tíktō). Arkhitékton é, portanto, o mestre de ofício ou mestre-construtor capaz de dirigir o trabalho alheio como o próprio em um todo harmônico.

Ademais, quando Gropius invocava uma arte arquitetônica, não estava se referindo apenas à atividade profissional responsável pela forma dos edifícios. "Arte" significava também um saber de natureza teleológica e referido ao produzir material. A palavra grega original é tékhnē. Logo, a rigor, a tékhnē arkhitektoniké era um saber geral e superior da produção das coisas que têm em si alguma finalidade ligada à vida e que apresentam entre si alguma coerência. E a expressão visual dessa coerência em cada povo ou período da história era o estilo.

Em seu diagnóstico de crise da arte, Gottfried Semper iluminou o que ainda se queria dizer com "arquitetura" em meados do século XIX. Ele nomeou basicamente aquilo que os reformadores almejavam: uma arte totalmente integrada com a vida, ou, em outras palavras, um antídoto para a arte de salão. Tentando formular o problema, Semper escreveu:

\footnotetext{
${ }^{2}$ A expressão "zweckentbunden" é incomum e de difícil tradução. De toda forma, não parece se opor ao funcionalismo na arquitetura que então emergia e da qual Walter Gropius será considerado um dos expoentes. Antes, remete possivelmente à dimensão puramente estética dos edifícios (ou de qualquer outra coisa) como descrita pela teoria estética moderna de Immanuel Kant. Em linhas gerais, essa teoria defende que a experiência estética é fundamentalmente independente da finalidade ou do uso daquilo que é experienciado. Pode também remeter simplesmente ao caráter monumental dos edifícios, categoria que Gropius ainda utiliza nos anos 1920. Ambas as interpretações são compatíveis com o argumento geral da passagem, a saber, de que a eticidade de uma nação se expressa sensorialmente nas suas obras concretas.
} 
Como eu posso explicar de maneira sucinta? Não está claro quando eu digo que a arte recorre ao artesanato, assim como antes o artesanato recorria à arte; pois não quero de forma alguma dizer que um sentido artesanal e não artístico teria se tornado dominante. Essa expressão justifica-se apenas na medida em que o impulso para refinar as formas já não vem de baixo, mas de cima. Mas mesmo essa interpretação é insatisfatória, pois o mesmo que acontecia com Fídias e no tempo de Rafael, acontecia de maneira ainda mais consequente com os antigos egípcios e sempre onde a arquitetura tinha domínio hierárquico sobre todas as outras artes. A anomalia consiste essencialmente apenas no fato de que essa influência vinda de cima ocorre em um tempo no qual não se reconhece uma arte da construção dominante, em um tempo intimamente relacionado com aquele, no qual, antigamente, o luxo construía seu ninho em tendas e fazendas. Assim, cada um segue o seu próprio caminho, e torna-se claro que, sob tais circunstâncias e condições, nenhuma postura firme pode ser mantida. (SEMPER, 1852, p. 36-37)

"Arquitetura" nomeava então um espírito comum, que tornaria possível a integração das artes e sua integração com a vida. Mais ainda: equivalia na arte a um fundamento social comum; a uma contraparte da mera atividade privada.

Não estranha, portanto, que o estilo moderno tenha em um primeiro momento se espelhado em um passado gótico: o que os seus proponentes desejavam era a unidade em si dos estilos históricos, mais do que qualquer atributo visual particular. Esta é a palavra recorrente nos textos de Gropius: Einheit. Ela indica o desafio de uma geração de artistas comprometida com a renovação social da arte.

\section{O novo estilo}

Antes mesmo do fechamento da Bauhaus, os efeitos do modernismo europeu fizeram-se sentir do outro lado do Oceano Atlântico. Nos Estados Unidos, o novo Museu de Arte Moderna de Nova York (MoMA) preparou em 1932 sua primeira exposição de arquitetura moderna a partir da observação de dez anos de produção, especialmente dos europeus Jacobus Johannes Pieter Oud, Le Corbusier (Charles-Édouard Jeanneret), Walter Gropius e Ludwig Mies van der Rohe. Além de organizar a exposição, Philip Johnson e Henry-Russell Hitchcock publicaram o livro intitulado The International Style: Architecture since 1922.

Como prefacia o então diretor do museu, Alfred H. Barr Jr., considerando um elenco de características formais e atitudes projetivas, os curadores reconheceram a existência de "um estilo moderno tão original, consistente, lógico e amplamente distribuído quanto qualquer outro do passado" (JOHNSON; HITCHCOCK, 1932, p. 27). Nesse momento, ao que parece, não mais se distinguiam e articulavam as acepções histórica e arquitetônica de estilo, o que justifica a acusação de formalismo feita posteriormente à ideia de Estilo Internacional (FRAMPTON, 1997, p. 303). Na edição de 1955, Johnson fez mea culpa, admitindo que, se fosse um arquiteto praticante na época, teria objeções ao termo (JOHNSON; HITCHCOCK, 1932, p. 16). Nos anos subsequentes, ele e Hitchcock reconheceram o limite do conceito de Estilo Internacional (JOHNSON; HITCHCOCK, 1932, p. 20). Hoje considera-se que o modernismo é muito mais diverso esteticamente. Não obstante, em 1932, os autores ainda tinham uma ideia do que "estilo" significava para os primeiros modernistas e sobre ela assentaram seu argumento:

Nós temos, assim como os egípcios ou os chineses tinham, assim como, antes de nós, os gregos e nossos antepassados na Idade Média, um estilo [...]. Independentemente dos tipos específicos de estrutura ou de função, o estilo tem uma estética definível. [...] Aqueles que 
enterraram a arquitetura, seja por um desejo frustrado de dar continuidade ao passado ou por uma ansiedade extrema de modificar e apressar o futuro, foram prematuros: nós ainda temos uma arquitetura. (JOHNSON; HITCHCOCK, 1932, p. 105-106)

Gropius foi arrolado entre os primeiros a alcançar a chamada "solução" do problema colocado pelos revivalistas ingleses (JOHNSON; HITCHCOCK, 1932, p. 35), principalmente por seus projetos em Dessau. Foi considerada também sua produção anterior à Primeira Guerra Mundial, como a Fagus-Werk em Alfeld an der Leine, projetada com Adolf Meyer em 1911.

No entanto, quem consolidou a visão do Gropius modernista foi o historiador da arte Nikolaus Pevsner. Em 1936, Pevsner publicou em Londres o primeiro ensaio compreensivo sobre a história do design e da arquitetura moderna, Pioneers of the Modern Movement, reeditado pelo MoMA em 1949. Seu objeto de estudo era nada menos do que as origens do "novo estilo, o estilo genuíno e legítimo do nosso tempo" (PEVSNER, 2011, p. 27). Pevsner escolheu o edifício projetado por Gropius e Meyer para a exposição do Deutscher Werkbund em Colônia em 1914 como a obra conclusiva do processo de surgimento do estilo moderno. Não parece, porém, que fazia uso do sentido arquitetônico de estilo. Pevsner referia-se estritamente a características formais, tendo em vista a novidade no uso dos novos materiais e métodos construtivos. Daí presume-se que opinião Gropius poderia ter dessa argumentação.

Nesse sentido, a exposição de 1938 do MoMA sobre a Bauhaus pôs à prova as convicções de Gropius. Ao que tudo indica, Herbert Bayer, Walter e Ise Gropius tiveram dificuldade de fazer entender seu sentido de arte arquitetônica, mesmo considerando o sucesso no meio norteamericano da chamada Bauhaus architecture (KENTGENS-CRAIG, 1999, p. xiv-xvi). A exposição foi ambivalente, por representar um momento decisivo da consolidação da imagem da Bauhaus de acordo com Gropius - considerando a exclusão do período sob a direção de Hannes Meyer e de Mies van der Rohe - e por ensejar, ao mesmo tempo, a disseminação da ideia de um Bauhaus style. A propósito, provavelmente temendo esse efeito, o protesto de Gropius contra tal estilo oito anos antes foi traduzido para o catálogo da exposição (BAYER; GROPIUS; GROPIUS, 1938, p. 206).

Ao que parece, a consolidação da imagem da Bauhaus nos Estados Unidos foi resultado de uma negociação com interesses institucionais dos museus e das universidades. Logo, a visão da Bauhaus como um estilo insere-se em um processo maior de atualização cultural que teve início na segunda metade dos anos 1920, por esforço de uma elite intelectual (PULOS, 1983). Pode-se dizer afinal que, tomada como um dado, a vanguarda artística europeia foi abreviada e posta a serviço de uma nova fase de expansão mundial da influência norte-americana. Consequentemente, as origens revivalistas que embasaram a proposta de uma escola da nova arte da construção foram paulatinamente esquecidas.

\section{Considerações finais}

Contemporaneamente, o espírito do estilo permanece envolto em uma névoa. Talvez tanto quanto o ecletismo do século XIX, a reação adversa de Walter Gropius ao uso da palavra tenha contribuído "para dar à própria ideia de estilo uma conotação negativa" (JOHNSON; HITCHCOCK, 1932, p. 34). Ao que tudo indica, já nos Estados Unidos dos anos 1930, a 
concepção moderna de arquitetura havia perdido alguma coisa que a conectava à tradição das artes e ofícios.

Nesse sentido, a redescoberta do sentido original do revivalismo gótico oferece uma chave de leitura proveitosa. A expressão, no entanto, foi ainda mais obscurecida que "estilo". Disso resulta a dificuldade para perceber à primeira vista como o revivalismo respondia no século XIX ao problema representado pelo historicismo na arte. O crítico Giulio Carlo Argan recupera esse sentido ao afirmar que

Naturalmente, o revival, como evocação que chega a ser onírica, não consiste numa imitação de formas antigas tomadas como modelos, mas na evocação do "espírito" de outros tempos ou de outras civilizações. Assim, a arquitetura moderna, especialmente quando aproveita materiais novos como o ferro e o concreto, evoca vagamente os ritmos do romântico ou do gótico, opondo essa livre evocação à imitação maçante e mesmo assim infiel dos "estilos". (ARGAN, 2010, p. 488)

Logo, para todos os efeitos, o revivalismo, a arte arquitetônica e o estilo moderno são três modalidades de oposição ao historicismo e ao ecletismo acadêmicos. Na passagem do século XIX para o XX, elas ainda se referenciavam umas às outras no discurso dos pioneiros; mas, como a progressiva institucionalização do Movimento Moderno, por meio de uma historiografia apologética da qual Nikolaus Pevsner é o melhor exemplo, o estilo moderno destacou-se das suas raízes. A partir daí, o diagnóstico de formalismo do estilo moderno ganhou ímpeto; porém, ele nada tem a ver com o que foi proposto na fundação da Bauhaus.

Por mais que a ideia de estilo soasse afinal antitética em relação aos objetivos da escola, ela sobreviveu no uso peculiar da palavra "arquitetura" no debate artístico que se estende ao menos de Pugin a Gropius. No mesmo sentido, a injunção para criar um estilo do próprio tempo não se referia tão somente à atualização das formas da arte, mas a uma transformação profunda da disposição dos artistas.

\section{Referências}

ARGAN, Giulio Carlo. A arte moderna na Europa: de Hogarth a Picasso [1983]. Tradução de Lorenzo Mammì. São Paulo: Companhia das Letras, 2010.

BAYER, Herbert; GROPIUS, Ise; GROPIUS, Walter. Bauhaus: 1919-1928. New York: Museum of Modern Art, 1938.

FRAMPTON, Kenneth. História crítica da arquitetura moderna [1980]. Tradução de Jefferson Luiz Camargo. São Paulo: Martins Fontes, 1997.

GROPIUS, Walter. Programm des staatlichen Bauhauses in Weimar. München: Bauhausverlag, 1919.

GROPIUS, Walter. Idee und Aufbau des staatlichen Bauhauses Weimar. München: Bauhausverlag, 1923.

GROPIUS, Walter. Scope of total architecture. New York: Harper \& Row, 1955.

JOHNSON, Philip; HITCHCOCK, Henry-Russell. The International Style. New York: W. W. Norton, 1932. 
KENTGENS-CRAIG, Margret. The Bauhaus and America: first contacts, 1919-1936 [1993]. Cambridge, Massachusetts: The MIT Press, 1999.

PEVSNER, Nikolaus. Pioneers of modern design: from William Morris to Walter Gropius [1936/1949]. Bath: Palazzo, 2011.

PUGIN, Augustus W. N. Contrasts, or, A parallel between the noble edifices of the fourteenth and fifteenth centuries, and similar buildings of the present day. London: St. Marie's Grange, 1836.

PUGIN, Augustus W. N. An apology for the revival of Christian architecture in England. Edinburgh: John Grant, 1895.

PULOS, Arthur. American design ethic: a history of industrial design to 1940. Cambridge, Massachusetts: The MIT Press, 1983.

ROMANS, Mervyn (ed.). Histories of Art and Design Education: Collected Essays. Bristol: Intellect Books, 2005.

SEMPER, Gottfried. Wissenschaft, Industrie und Kunst. Braunschweig: Friedrich Vieweg und Sohn, 1852.

WICK, Rainer. Pedagogia da Bauhaus [1982]. Tradução de João Azenha Jr. São Paulo: Martins Fontes, 1989.

WILLIAMS, Raymond. Culture and society, 1780-1950 [1958]. Garden City, New York: Doubleday \& Company, 1960.

WINGLER, Hans Maria. The Bauhaus: Weimar, Dessau, Berlin, Chicago [1962]. Cambridge, Massachusetts: The MIT Press, 1978.

\section{Sobre o autor}

Felipe Kaizer é designer e pesquisador. Graduado pela Pontifícia Universidade Católica do Rio de Janeiro (PUC-Rio, 2006), pós-graduado pelo Centro Universitário Maria Antonia da Universidade de São Paulo (CEUMA/USP, 2013) e doutor em design pela Escola Superior de Desenho Industrial da Universidade Estadual do Rio de Janeiro (ESDI/UERJ, 2019). Entre 2009 e 2018, trabalhou na Fundação Bienal de São Paulo e no Instituto Moreira Salles.

fk@felipekaizer.com 